\title{
Inverter Control Scheme with the Function of Current and Voltage Harmonics Composite Suppression and the Application Analysis of Micro-Grid
}

\author{
Xu chengcheng ${ }^{1, a}$, Chen $\mathrm{Xin}^{2, \mathrm{~b}}$, Zhang Changhua ${ }^{2, \mathrm{~b}}$ \\ ${ }^{1}$ Electronic Experiment Center, Chengdu University of Information Technology, Cheng Du \\ 610225, China; \\ ${ }^{2}$ School of Energy Science and Engineering, University of Electronic Science and \\ Technology of China, Chengdu, 611731, China \\ aemail: twtbddn@cuit.edu.cn, bemail:ainks517@163.com
}

Keywords: Micro-grid; Inverter; Comprehensive suppress harmonics; Droop control.

\begin{abstract}
An improved controller design method for an inverter operating with extra functions to suppress current harmonics or voltage harmonics is proposed. When at least two of this-type inverters are operating in a micro-grid, they can collaboratively bear current harmonics and voltage harmonics suppression tasks respectively. This would benefit the micro-grid further wide applications. In this paper, firstly, the principles of harmonics comprehensive suppression are analyzed. Then, two kinds of inverter controllers with different harmonics suppression purposes are designed. Finally, the effectiveness of the above control strategies is verified by Matlab/Simulink simulation results. The total harmonic distortion (THD) values of current and voltage are obviously reduced when these two inverters are connected in parallel with the micro-grid.
\end{abstract}

\section{Introduction}

As a special organization of distributed generation, micro-grid which is a combination of renewable energy sources, storage energy devices and loads, becomes the focus of research field [1]. The renewable energy sources often form micro-grid via power inverters. And mostly, the loads connected to the micro-grid are non-linear. All these conditions cause such problems, harmonic current distortion in grid and linear load branches, and the harmonic voltage distortion in point of common coupling (PCC) [2], [3]. The harmonic distortion impacts productivity of inverter and loads. More seriously, even cause system instability.

Aiming at reducing the current and voltage THD of micro-grid, several control schemes have been proposed. In the aspect of reducing the harmonics current, active power filter (APF) is widely used [4]. However, as penetration of micro-grid is increasing, the equipment cost increases as well due to each micro-grid has an APF. Since inverter and APF have the same power electronic topologies, several strategies which are combinations of power delivery and harmonic current suppression have been developed [5], [6], [7]. These strategies often ignore the voltage harmonic suppression. Do to reduce the harmonics voltage, a harmonic droop controller is proposed to reduce the voltage harmonics of inverters [8], however, it further worsens the current THD. Obviously, if load in micro-grid is sensitive to both current and voltage harmonics, it will be necessary to assure the quality of the current and voltage of the micro-grid. Regarding of this problem, a new strategy focusing on comprehensive suppressed the current harmonic and the voltage harmonic simultaneously is proposed in this paper. This strategy applied two inverters operated in parallel. In this case, it is well understood that power sharing is a problem that must be solved. Many strategies are developed to this problem [9], [10], [11]. Among them, the strategy in [11] has better performance for accurate proportional load sharing among inverters operated in parallel. Part of this work is therefore carried out based on [11].

The rest of this paper is organized as follows. Firstly, a mathematic model of micro-grid is proposed. And the principles of harmonics comprehensive suppression are analyzed. Secondly, two kinds of inverter controller with different harmonics suppression are proposed. Simulation results 
and analysis are given in the next, followed by conclusions in the end.

\section{Mathematic Model of Micro-grid and Principles of Harmonic Suppression}

The structure of micro-grid is composed of linear load, non-linear load, and two inverters DG1 and DG2. In this paper, it is assumed that DG1 is to compensate voltage harmonics while DG2 is to compensate current harmonics respectively. Then, the mathematical model of micro-grid can be illustrated as shown in Fig. 1 . Where DG1, DG2 are modelled as voltage references $u_{\mathrm{r} 1}, u_{\mathrm{r} 2}$ with output impedances $Z_{01}, Z_{02}$ respectively. The grid and loads are modelled as the combination of voltage and current sources, where $i_{\mathrm{g}}$ is grid current, $i_{\mathrm{L}}$ is linear load branch current and $i_{\mathrm{N} 1} \ldots i_{\mathrm{N} h}$ are fundamental current and harmonic currents of non-linear loads branch ( $h$ is harmonics times).

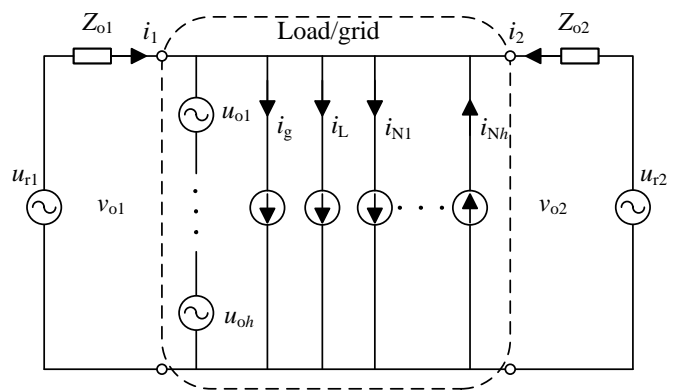

Fig.1. The mathematical model of micro-grid.

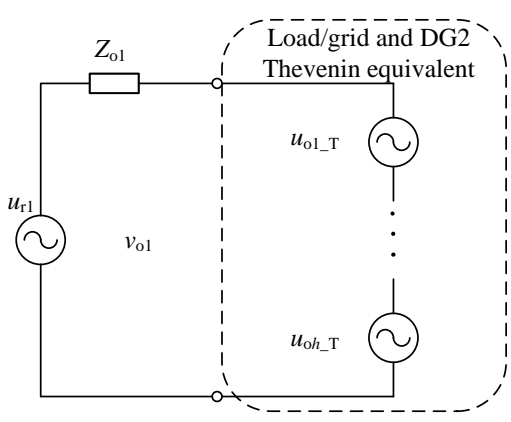

Fig.2. Thevenin equivalent of micro-grid.

According to KCL theorem, stead state current of each branch is described as:

$$
-i_{1}-i_{2}+i_{\mathrm{g}}+i_{\mathrm{L}}+i_{\mathrm{N} 1}-\sum i_{\mathrm{N} h}=0
$$

Where $\Sigma i_{\mathrm{Nh}}=i_{\mathrm{N} 2}+i_{\mathrm{N} 3} \ldots i_{\mathrm{N} h}$, if $i_{2 h}$ has the equal amplitude and the opposite phase with $\left(i_{1 h}+i_{\mathrm{Nh}}\right)$ at each harmonic frequency, Grid current $i_{\mathrm{g}}$ and linear loads branch current $i_{\mathrm{L}}$ are expected to be zero.

When system becomes stable, and control interaction between DG1 and DG2 is ignored, via Thevenin equivalent theory, the model in Fig. 1 can be redrawn as shown in Fig. 2. For each $h$ order, if the $h$ harmonic component of $v_{\mathrm{ol}}$ has the equal amplitude and the opposite phase with $u_{\mathrm{o}{ }_{-}} \mathrm{T}$, the voltage harmonics at PCC are approximately zero.

\section{Controller with Suppress Current and Voltage Harmonics}

\section{A. Suppress Voltage Harmonics}

In order to suppress voltage harmonics, output voltage of the inverter (DG1) must has the same amplitude but opposite phase with $u_{\mathrm{oh}-\mathrm{T}}$ at each harmonic frequency. Therefore, a parallel structure with multiple control loops for multi-functions of energy conversion and voltage harmonics suppression is shown in Fig. 3. Where $\Sigma v_{\mathrm{o}}$ and $\Sigma i_{h}$ are the total harmonic output voltage and output current of inverter. The dotted box is virtual impedance, if the gain $K_{\mathrm{i}}$ is chosen big enough, the output impedance of inverter can be made nearly purely resistive over a wide range of frequencies. The fundamental droop controller was designed according to [11], combined with virtual impedance, it has a good performance for proportional load sharing. On the other hand, at each harmonic frequency, droop characteristics is always expressed as below, irrespective the type of load:

$$
E_{h}=E_{h}{ }^{*}-m_{h} P_{h} \quad \text { (2) } \omega_{h}=\omega_{h}^{*}-n_{h} Q_{h}
$$

Practically, amplitude of each voltage harmonic would never achieve zero, although voltage harmonics suppression method is taken. Therefore, a negative feedback loop $K_{\mathrm{eh}}\left(E_{h}{ }^{*}-v_{h \mathrm{rms}}\right)$ is added. The degree of harmonic suppression is controlled via $E_{h}{ }^{*}$. This paper sets $E_{h}{ }^{*}$ as the $5 \%$ rated voltage reference. Based on these analysis, the $h$ th-harmonic droop controller is designed as shown in Fig. 4. 


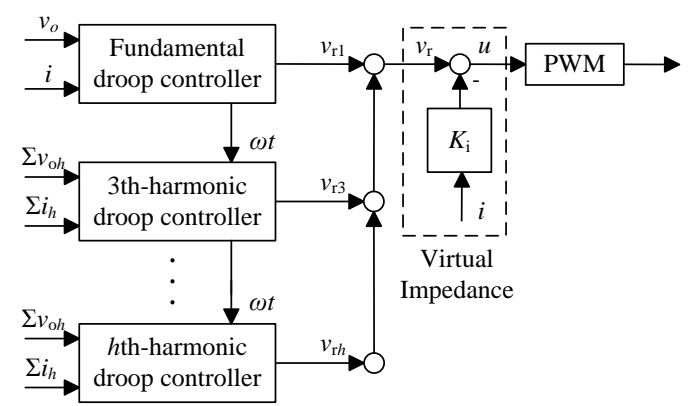

Fig.3. Controller with the function of voltage harmonic suppression.



Fig.4. hth-harmonic droop controller.

\section{B. Suppress Current Harmonics}

As discussed previously, in order to force the $h$ th current harmonics in the $i_{\mathrm{g}}$ and the $i_{\mathrm{L}}$ to be zero, the $\left(i_{2 h}+i_{1 h}+i_{\mathrm{Nh}}\right)$ needs to be zero. In other words, $i_{2 h}$ which is output current of the inverter (DG2) must has the same amplitude but the opposite phase with $\left(i_{1 h}+i_{N h}\right)$ at each $h$ order. Considering the PR algorithm has good performance of tracking the sinusoidal signal. Therefore, use multiple PR loops connect parallel, each PR loop tracks one harmonic frequency. Together with the fundamental droop controller and virtual impedance, to form a novel inverter controller with multi-functions of electric energy conversion and current harmonics suppression, just like shown in Fig.5.

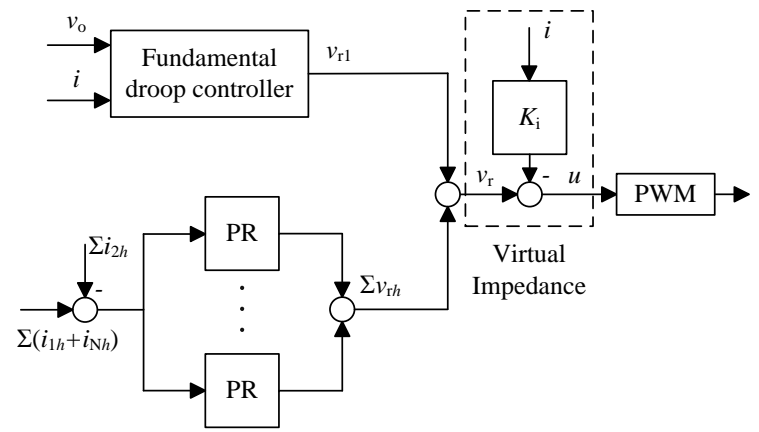

Fig.5. Controller with the function of current harmonic suppression.

The transfer function of PR loop is depicted as follows:

$$
G_{\mathrm{PR}}(s)=K_{\mathrm{P}}+\frac{2 K_{\mathrm{I}} \omega_{\mathrm{c}} s}{s^{2}+2 \omega_{\mathrm{c}} s+\omega_{0}^{2}}
$$

Where $\omega_{\mathrm{c}}$ is cutoff frequency. $\omega_{0}$ is resonant frequency. $K_{\mathrm{P}}$ is the proportional gain. $K_{\mathrm{I}}$ is resonant gain. Its parametric characteristic has been discussed by [6], [7].

\section{Simulation results and analysis}

To evaluate performance of the proposed control scheme, micro-grid models have been built via Matlab/Simulink. A single phase system is presented with following parameters. The system nominal voltage is $220 \mathrm{~V}$ and its nominal frequency is $50 \mathrm{~Hz}$. Power cables are typical low-voltage cables, with $150 \mathrm{~m}$ length. The PR controller parameters as: $K_{\mathrm{P}}=6.7, K_{\mathrm{I}}=93.3, \omega_{\mathrm{c}}=2.5 \mathrm{rad} / \mathrm{s}$. The droop coefficients in $h$ th-harmonic droop controller are: $m_{h}=13.88, n_{h}=720.7, K_{\mathrm{e} h}=2$. Inverters both use LC filter, $L=2.35 \mathrm{mH}, C=22 \mu \mathrm{F}$. The non-linear load is an uncontrolled rectifier with RLC load, where $R_{\mathrm{NL}}=3 \Omega, L_{\mathrm{NL}}=0.15 \mathrm{mH}, C_{\mathrm{NL}}=1 \mathrm{mF}$. The linear load is RLC load, rated active power $10 \mathrm{~kW}$, rated inductive reactive power $1 \mathrm{kVar}$, rated capacitive reactive power $0.5 \mathrm{kVar}$. Simulations are carried out with two situations: off grid mode and grid connected mode.

\section{A. Simulation of off-grid operation}

When micro-grid operates in off-grid mode, improving the power qualities of the current flowing through the branch connected with the sensitive linear load and the voltage at PCC is the tasks of DG1 and DG2. The simulation are carried out under four situations: 1) Harmonics suppression function of DG1 and DG2 are both disabled; 2) DG1 is enabled harmonic voltage suppression 
function but DG2 is disabled harmonic current suppression function; 3) DG2 is enabled harmonic current suppression function while DG1 disabled harmonic voltage control function; 4) Harmonic suppression function of DG1 and DG2 are both enabled. The simulation results were shown in Fig. 6. The THD values of each situation are also shown in TABLE. I . Obviously, the waveforms of current and voltage were getting closer to a standard sinusoidal waveform from situation 1) to 4). For situation 4), the THD of current and voltage were $7.57 \%$ and $5.41 \%$ respectively, both obviously decreasing with that in situation 1). This results proves the effectiveness of strategies presented in this paper.

TABLE I. THE THD OF CURRENT AND Voltage IN Fig.6.

\begin{tabular}{|l|l|l|}
\hline & The THD of current & The THD of voltage \\
\hline situation: 1) & $20.46 \%$ & $19.17 \%$ \\
\hline situation: 2) & $11.66 \%$ & $9.38 \%$ \\
\hline situation: 3) & $8.79 \%$ & $6.66 \%$ \\
\hline situation: 4) & $7.57 \%$ & $5.41 \%$ \\
\hline
\end{tabular}
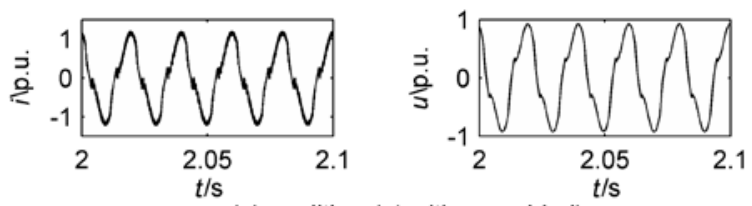

(a)condition 1 (neither enabled)
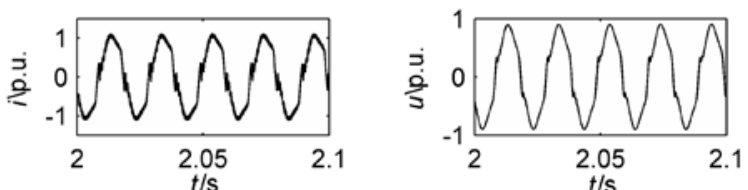

(b)condition 2 (only enable voltage harmonic control)
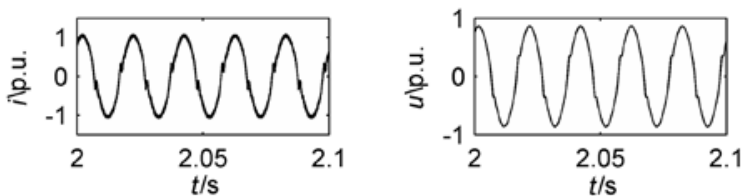

(c)condition 3 (only enable current harmonic control)
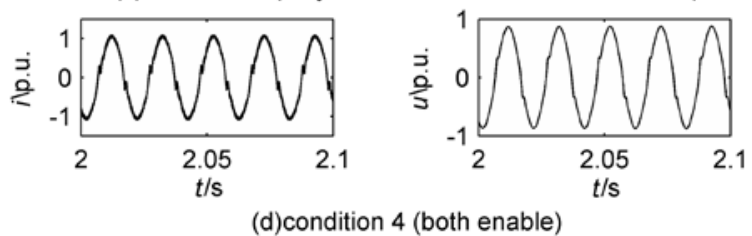

Fig.6. Simulation waveforms of off-grid operation.

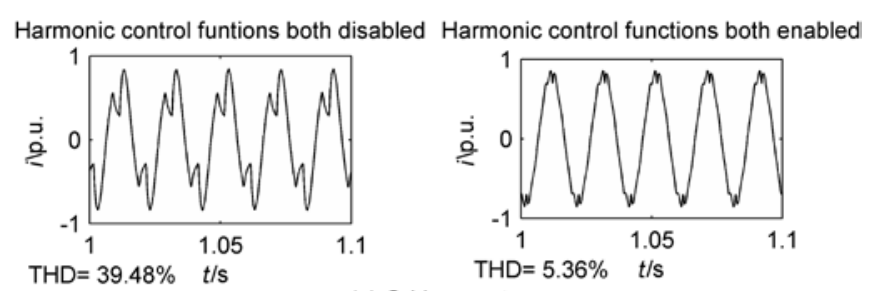

(a) Grid current
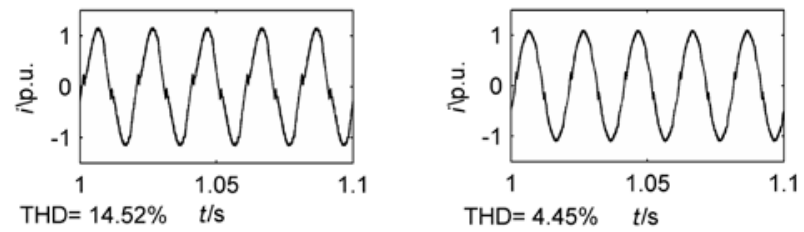

(b) Linear load branch current

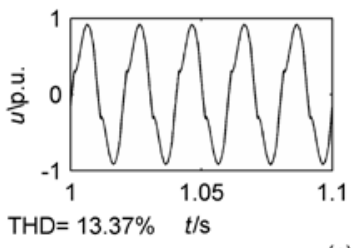

(c) PCC voltage

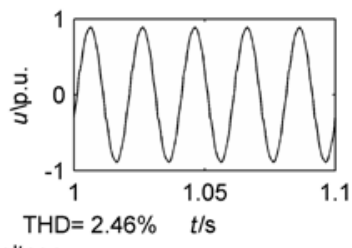

Fig.7. Simulation waveforms of grid-connected operation.

\section{B. Simulation of grid-connected operation}

When micro-grid operates in grid-connected mode, improving power qualities of current injecting into grid is the tasks of DG1 and DG2. Simulations are carried out under two situations: 1) Harmonic suppression function of DG1 and DG2 are both disabled; 2) Harmonic suppression function of DG1 and DG2 are both enabled. The simulation waveforms and the THD are shown in Fig. 7. Noting the fact that the grid branch has lower impedance than the linear load branch at harmonic frequencies. For situation 1), the THD of current flowing through branch connecting with the grid was 39.48\%, much larger than that in branch with linear load (14.52\%). For situation 2), the current THD in above two branches were both suppressed to nearly 5\%. And the THD of voltage of PCC was $2.46 \%$. These harmonics distortion is acceptable. 


\section{Conclusion}

After proposing a modeling method for micro-grid system, it has been found out that the harmonics current and voltage in micro-grid can be treated simultaneously by two inverters operated in parallel. Then two strategies to suppress current harmonics or voltage harmonics are proposed. The proposed strategies are able to significantly reduce the harmonic components in the current and voltage. Finally, the effectiveness of the proposed strategies is verified with simulation.

\section{References}

[1] J. Guerrero, J. Vasquez, J. Matas, M. Castilla, and L. de Vicuna. Control strategy for flexible microgrid based on parallel line-interactive UPS systems[J], IEEE Trans. Ind. Electron., 2009, 56(3), 726-736.

[2] T. Hornik and Q.-C. Zhong. A current control strategy for voltage-source inverters in microgrids based on $\mathrm{H} \infty$ and repetitive control[J], IEEE Trans. Power Electron., 2011,26(3), 943-952.

[3] N. Yousefpoor, S. Fathi, N. Farokhnia, and H. A. Abyaneh. THD minimization applied directly on the line to line voltage of multi-level inverters[J], IEEE Trans. Ind. Electron., 2012, 59(1), 373-380.

[4] R. Costa-Castello, R. Grino, R. Cardoner, and E. Fossas, "High performance control of a single-phase shunt active filter," in Proc. IEEE ISIE, 2007, 3350-3355.

[5] M. Castilla, J. Miret, J. Matas, and Luis García de Vicuña. Reduction of current harmonic distortion in three-phase grid-connected photovoltaic inverters via resonant current control[J], IEEE Trans. Ind. Electron., 2013, 60(4), 1464-1472.

[6] G. Shen, X. Zhu, J. Zhang, and D. Xu. A new feedback method for PR current control of LCL-filter-based grid-connected inverter[J], IEEE Trans. Ind. Electron.,2010, 57(6),2033-2041.

[7] F. Gonz'alez-Espin, G. Garcer'a, I. Patrao, and E. Figueres. An adaptive control system for three-phase photovoltaic inverters working in a polluted and variable frequency electric grid[J], IEEE Trans. Power Electron.,2012, 27(10), 4248-4260.

[8] Qing-Chang Z. Harmonic Droop Controller to Reduce the Voltage Harmonics of Inverters[J], IEEE Trans. Ind. Electron.,2013, 60(3), 936-945.

[9] J. Guerrero, J. Matas, L. G. de Vicuna, M. Castilla, and J. Miret. Decentralized control for parallel operation of distributed generation inverters using resistive output impedance[J], IEEE Trans. Ind. Electron., 2007, (54), 994-1004.

[10]W. Yao, M. Chen, J. Matas, J. Guerrero, and Z.-M. Qian. Design and analysis of the droop control method for parallel inverters considering the impact of the complex impedance on the power sharing[J], IEEE Trans. Ind. Electron., 2011, (58), 576-588.

[11]Q.-C. Zhong. Robust droop controller for accurate proportional load sharing among inverters operated in parallel[J], IEEE Trans. Ind. Electron., 2013, 60(4), 1281-1290. 